\title{
Öğretmenlerin Nomofobi Düzeylerinin Demografik Özelliklerine ve Akıllı Telefon Kullanım Alışkanlıklarina Göre İncelenmesi
}

DOI: 10.26466/opus.676329

\author{
Ezgi Pelin Ylldız - Metin Çengel ${ }^{* *}$-Ayşe Alkan ${ }^{* * *}$
}

* Dr. Öğr. Üyesi, Kafkas Üniversitesi/Kazım Karabekir Teknik Bilimler MYO/Kars/Türkiye

E-Posta: yildizezgipelin@kafkas.edu.tr

ORCID: 0000-0002-9987-9857

** Dr. Öğr. Üyesi, Sakarya Uyg Bilim.Üniversitesi/Hendek Teknik Bilimler MYO/Sakarya/Türkiye

E-Posta: cengel@sakarya.edu.tr

ORCID: 0000-0001-6049-5015

*** Doktor, Samsun İl Milli Eğitim Müdürlüğü/Samsun/Türkiye

E-Posta: ayshe alkan@hotmail.com

ORCID: $\underline{0000-0002-9125-1408}$

\section{Öz}

Günümüz hastalığı olarak kabul gören nomofobi, cep telefonundan mahrum kalma korkusu olarak tanımlanmaktadır. Bu araştırmanın amacı öğretmenlerin nomofobi düzeylerinin demografik özelliklerine ve akllı telefon kullanım alışkanlıklarına göre değişimlerini ortaya koymaktır. İlişkisel tarama modelinde yürütülen araştırmanın çalışma grubunu, Sakarya ilinde kamu ve özel eğitim kurum ve kuruluşlarında görev yapan 290 öğretmen oluşturmaktadır. Araştırmada veri toplama aracı olarak Merlo, Stone ve Bibbey (2013) tarafindan geliştirilen Problemli Akıllı Telefon Kullanımı ve Ön Psikometrik Özellikleri Ölçeği'nden yararlanılmıştır. Araştırma sonucuna göre öğretmenlerin cinsiyet, eğitim durumu, branş, çalışılan kurum ve mesleki kıdemleri gibi demografik özellikleri ile nomofobi düzeyleri arasında anlamlı bir farkllık olmadığ buna rağmen yaş değişkeni ile nomofobi düzeyi arasinda anlaml bir farklllğ̆m olduğu tespit edilmiştir. Bir diğer sonuç öğretmenlerin akıll telefon kullanım yılına göre nomofobi düzeylerinde anlaml fark görülmezken; akıllı telefonların şarj etme ve kontrol etme aralı̆̆ ile akıllı telefonların unutunca panik olma durumları arasında anlamlı bir fark olduğu saptanmiştır.

Anahtar Kelimeler: Nomofobi, akıllı telefon, akıllı telefon kullanım alışkanlıkları, öğretmenler, demografik özellikler 


\title{
Investigation Of Teachers 'Nomophobia Levels According To Demographic Characteristics And Smartphone Use
}

\begin{abstract}
Nomophobia, which is accepted as the disease of today, is defined as fear of being deprived of mobile phone. The aim of this study is to reveal the changes in the nomophobia levels of teachers according to their demographic characteristics and smartphone usage habits. The study group of the research conducted in the relational screening model consists of 290 teachers working in public and private educational institutions and organizations in Sakarya province. In the study, measuring problematic mobile phone use: Development and Preliminary Psychometric Properties of the PUMP Scale adapted by Merlo, Stone and Bibbey (2013) were used as data collection tools. According to the results of the study, there was no significant difference between the demographic characteristics of teachers such as gender, educational background, branch, institution and professional seniority, and there was a significant difference between age variable and nomophobia level. Another result is that there is no significant difference in nomophobia levels of teachers according to smart phone usage year; It was found that there was a significant difference between the range of charging and controlling smart phones and panic situations when they forgot their smart phones..
\end{abstract}

Keywords: Nomophobia, smartphone, smartphone usage habits, teachers, demographic features 


\section{Giriş}

Bilgi ve iletişim teknolojilerinde yaşanan hızlı gelişim ve değişimler bireylerin yaşantılarında pek çok değişim ve kolaylığı beraberinde getirmiştir. Özellikle tablet bilgisayar, notebook, PDA, akıllı telefon gibi mobil cihazlar yaşantımızın vazgeçilmez cihazları halini almıştır. Bu durumun istatistiksel verilerle açıklanabilirliği de ortadadır. Bu bağlamda TUIK 2019 verileri incelendiğinde; yetişkin insanların \%98'inin cep telefonu, bunların \%77'sinin ise akıllı telefon kullandıkları ortaya konulmuştur. Bireylerin akıllı telefonlara olan bu düşkünlüğü bir takım psikolojik rahatsızlıkların da ortaya çıkmasına zemin hazırlamıştır.

Connecticut Üniversitesi araştırmacısı David Greenfield bahsedilen bu psikolojik rahatsızlığ İngilizce de “NO MOBILE PHONE” kelimelerinin birleşmesinden meydana gelen Nomophobia (Nomofobi) kelimesi ile tanımlamıştır. Nomofobinin klinik psikolojide tanımı ise; "bireylerin akıllı telefonlarına erişemediği ve/veya akıllı telefonları üzerinden diğer kişilerle iletişime geçemediği zamanlarda yaşadıkları mantık dışı ve istemsiz korku olarak tanımlanmaktadır (King ve diğ., 2013; Yildirim ve Correia, 2015). İlgili literatür incelendiğinde nomofobinin farklı davranış ve semptomlarının olduğu gözlenmektedir. Nomofobik davranış ve semptomları gösteren bireyler, akıllı telefonları yanında olmadıklarında, şarjları bittiğinde ve/veya cihazları kapsama alanı dışında olduğunda ansızın kaygı duymaya başlarlar hatta cihazları yanlarında olsa bile obsesif bir şekilde kontrol etme gerekliliği hissederler (Adnan ve Gezgin, 2016; Algül, 2014; Dixit ve diğ., 2010; Gezgin ve Çakır, 2016; Pavithra ve Madhukumar, 2015; Sharma, Sharma, Sharma ve Wavare, 2015; Yildirim, Sumuer, Adnan, ve Yildirim, 2015). Bu tür davranışların yanı sıra sağlık boyutunda baş dönmesi, nefes darlığı, mide krampları, anksiyete gibi semptomların varlığı da nomofobi adına dikkat çekicidir (Thomee, Harenstam ve Hagberg, 2011).

Alan yazın incelendiğinde Erdem ve diğerleri (2016), 312 üniversite öğrencisiyle gerçekleştirdikleri çalışmada, nomofobinin akademik başarıya olan etkisini belirlemeyi amaçlamışlardır. Araştırmanın sonucunda katılımcılarının \%55'nin nomofobik olduğu tespit edilmiştir. Sharma vd., (2015), araştırmalarında nomofobiklik durumuna yönelik tıp fakültesi öğrencileriyle çalışmışlar sonuç olarak tıp fakültesi öğrencilerinden oluşan katılımcıların 
yaklaşık \%73'ünün nomofobik olduğu ve \%83'ünün mobil cihazlarına erişememe durumunda panik atak geçirecekleri belirlenmiştir. Bu durumun nomofobinin bireylerin yaşantılarını olumsuz düzeyde etkileyebilecek sonuçlar doğurabileceği düşünülmektedir. Gezgin, vd., (2019), araştırmalarında 608 okul öncesi öğretmenleri ile çalışmışlar, sonuç olarak akıllı telefonlarındaki mobil interneti sosyal ağlara girme, fotoğraf çekme ve düzenleme, internette gezinme (sörf yapma) amaciyla kullanan okul öncesi öğretmenlerinin nomofobi düzeylerinin anlamlı farklılık oluşturduğunu tespit etmişlerdir.

\section{Amaç}

Bu çalışmada, öğretmenlerin nomofobi düzeylerinin demografik özelliklerine ve akıllı telefon kullanım alışkanlıklarına göre incelenmesi amaçlanmıştir.

\section{Alt Amaçlar}

- Öğretmenlerin nomofobi düzeyleri demografik özelliklerine (cinsiyet, yaş, eğitim durumu, branş, çalışılan kurum, kademe, medeni durum, bilgisayar eğitimi, mesleki kıdem) göre anlamlı farklılık göstermekte midir?

- Öğretmenlerin nomofobi düzeyleri akıllı telefonları kullanım alışkanlıklarına (kullanım yıll, şarj süresi, adedi, interneti sürekli açı tutma durumu, günlük kullanım süresi, kontrol sıklığı, unutunca panik olma durumu, araç kullanırken kullanım, araçta metin, mesaj, e-mail yazma, kullanım amaçları) göre anlamlı farklılık göstermekte midir?

- Öğretmenlerin nomofobi düzeyleri ile akıllı telefonlarını şarj etme aralığı ile anlamlı bir ilişki var mıdır?

- Öğretmenlerin nomofobi düzeyleri ile akıllı telefonlarını kontrol etme aralığı ile anlamlı bir ilişki var mıdır?

- Öğretmenlerin nomofobi düzeyleri ile akıllı telefonlarını evde ya da işyerlerinde unutunca panik olma durumları ile anlamlı bir ilişki var mıdir? 


\section{Önem}

Bu araştırmada kamu ve özel sektörde çalışan çeşitli branşlardaki öğretmenlerin nomofobi düzeyleri çeşitli değişkenler açısından tespit edilmeye çalışılmıştır. Alan yazın incelendiğinde nomofobinin bireylerin hayatlarına getirdiği olumsuz etkiler açıktır. Bu olumsuz etkilere çeşitli sektörlerde ve branşlardaki öğretmenlerin maruz kalıp kalmadıkları şüphesiz ki merak konusudur. Araştırmanın bu bağlamda gelecekteki çalışmalara örnek olabileceği düşünülmekle birlikte olumsuz etkiler söz konusu ise bu konuda öğretmenlere yönelik düzenlenebilecek eğitimlere yön verebileceği öngörülmektedir.

\section{Yöntem}

$\mathrm{Bu}$ araştırma nicel araştırma yöntemlerinden ilişkisel tarama yöntemi ile gerçekleştirilmiştir. Illişkisel tarama yöntemi, değişkenler arasındaki ilişkileri belirlemek ve muhtemel sonuçları tahmin için kullanılmaktadır (Cresswell, 2017).

\section{Çalışma Grubu}

Araştırma grubunu oluştururken amaca uygun ve kolay ulaşılabilmesi için amaçlı örnekleme yöntemi kapsamında uygun örneklemeden yararlanılmıştır. Uygun örnekleme, araştırmacının kolaylıkla ulaşabileceği örneklem elemanlarını almayı içerir (Monette, Sullivan ve Dejong, 2005). Araştırmanın örneklemini Sakarya ilinde kamu ve özel eğitim kurum ve kuruluşlarında görev yapan 290 öğretmen oluşturmaktadır.

\section{Veri Toplama Araci}

Bu çalışmada, öğretmelerin nomofobi düzeylerinin belirlenmesi adına Merlo, Stone ve Bibbey (2013) tarafından geliştirilen problemli akıllı telefon kullanımı ve ön psikometrik özellikleri ölçeğinden yararlanılmıştır. AFA sonucunda ölçeğin öz değeri 1'den büyük 20 maddeden oluşan 2 faktörlü yapıs1, toplam varyansın \%59'unu açıklamaktadır. Veri toplama aracı için Cronbach alpha güvenirlik katsayısı .94'dür.

\section{Verilerin Analizi}


Araştırmadan elde edilen verilerin değerlendirilmesi ve tabloların oluşturulması amaciyla SPSS (Statistical Package for Social Sciences) versiyon 23 kullanılmıştır. Alt amaçları yanıtlamaya yönelik olarak toplanan verilerin analizinde yüzde (\%), ortalama (x), frekans (f) ve standart sapma (SS) kullanılmıştır. Yapılan Kolmogorov- Smirnov testi kapsaminda $p>0.05$ değeri elde edildiğinden verilerin normal dağılım gösterdiği kabul görmüştür. Bu bağlamda araştırmada parametrik testlerden; Tek Yönlü Anova testi kullanılmıştır. Verilerin farklarının açıklanmasında ise genel ortalama dikkate alınmıştır.

Tüm istatistiksel analizlerde anlamlılık düzeyi olarak 0.05 değeri kabul edilmiştir. İlgili ankete yönelik maddelerin ortalama ve standart sapma değerleri tablolar yardımıyla ortaya konulmuştur.

\section{Demografik Veriler}

Çalışmanın örnekleminde kullanılan öğretmenlerin demografik veriler aşağıdaki gibidir:

Cinsiyet: Araştırmaya katılan örneklem grubundan 290 kişinin 159'unun "kadın", 131'inin “erkek" olduğu tespit edilmiştir.

Yaş: Araştırmaya katılan örneklem grubundan 290 kişinin yaş ortalamasının yoğunlukla "40 yaş ve üzeri” olduğu tespit edilmiştir.

Ĕ̆itim Durumu: Araştırmaya katılan örneklem grubundan 290 kişinin eğitim durumlarının yoğunlukla "lisans" düzeyi olduğu tespit edilmiştir.

Branş: Araştırmaya katılan örneklem grubundan 290 kişinin branşlarının yoğunlukla "sınıf öğretmenliği" branşı olduğu tespit edilmiştir.

Çalışılan Kurum:Araştırmaya katılan örneklem grubundan 290 kişinin çalıştıkları kurumun yoğunlukla "kamu" kurumu olduğu tespit edilmiştir.

Kademe Araştırmaya katılan örneklem grubundan 290 kişinin çalıştıkları kademenin yoğunlukla "lise" kademesi olduğu tespit edilmiştir. 
Medeni Durum: Araştırmaya katılan örneklem grubundan 290 kişinin medeni durumlarının yoğunlukla "evli" olduğu tespit edilmiştir.

Bilgisayar Ĕ̆itimi: Araştırmaya katılan örneklem grubundan 290 kişinin çoğunun bilgisayar eğitimi aldığı tespit edilmiştir.

Mesleki Kıdem: Araştırmaya katılan örneklem grubundan 290 kişinin mesleki kıdeminin yoğunlukla "1-5 yıl" arasında olduğu tespit edilmiştir.

Tablo 1. En Çok Kullanılan Sosyal Medya Araçları

\begin{tabular}{lll}
\hline Sosyal Medya Araçları & $\mathbf{N}$ & $\mathbf{\%}$ \\
\hline Facebook & 46 & 15.9 \\
\hline Instagram & 74 & 25.5 \\
\hline Twitter & 16 & 5.5 \\
\hline YouTube & 136 & 46.9 \\
\hline Whatssapp & 120 & 4.1 \\
\hline Pinterest & 2 & .7 \\
\hline Diğer & 4 & 1.4 \\
\hline Toplam & $\mathbf{2 9 0}$ & $\mathbf{1 0 0}$ \\
\hline
\end{tabular}

Yukarıdaki tablo incelendiğinde araştırmaya katılan öğretmenlerin en çok kullandıkları sosyal medya aracının "YouTube" olduğu saptanmıştır.

Tablo 2. Akıllı Telefon Kullanım Yilı

\begin{tabular}{lll}
\hline Kullanim Yllh & $\mathbf{N}$ & $\%$ \\
\hline 1 yldan az & 2 & .7 \\
\hline $1-2$ & 3 & 1.0 \\
\hline $3-4$ & 23 & 7.9 \\
\hline $5-6$ & 87 & 30.0 \\
\hline $6+$ & 175 & 60.3 \\
\hline Toplam & $\mathbf{2 9 0}$ & $\mathbf{1 0 0}$ \\
\hline
\end{tabular}

Yukarıdaki tablo incelendiğinde araştırmaya katılan öğretmenlerin akıllı telefonları kullanım yılının sıklıkla "6 yıl ve daha fazlası" olduğu tespit edilmiştir. 
Tablo 3. Akıllı Telefonları Şarj Süresi

\begin{tabular}{lll}
\hline Şarj Süresi & $\mathbf{N}$ & $\mathbf{\%}$ \\
\hline 2 saatten az & 2 & .7 \\
\hline 2 saatte bir & 3 & 1.0 \\
\hline 3 saatte bir & 23 & 7.9 \\
\hline 4 saat ve fazlası & 87 & 30.0 \\
\hline Toplam & $\mathbf{2 9 0}$ & $\mathbf{1 0 0}$ \\
\hline
\end{tabular}

Yukarıdaki tablo incelendiğinde araştırmaya katılan öğretmenlerin akıllı telefonlarını şarj etme sürelerinin sıklıkla " 4 saat ve fazlası" olduğu tespit edilmiştir.

\section{Tablo 4. Akıllı Telefon Adedi}

\begin{tabular}{lll}
\hline Adet & $\mathbf{N}$ & $\mathbf{\%}$ \\
\hline 1 & 273 & 95.1 \\
\hline 2 & 13 & 4.5 \\
\hline 2 ve fazlasi & 4 & .4 \\
\hline Toplam & $\mathbf{2 9 0}$ & $\mathbf{1 0 0}$ \\
\hline
\end{tabular}

Yukarıdaki tablo incelendiğinde öğretmenlerin kullandığı akıllı telefon adetinin sıklıkla "1" olduğu tespit edilmiştir.

\section{Tablo 5. Interneti Sürekli Açık Tutma}

\begin{tabular}{lll}
\hline İnterneti Açık Tutma & N & \% \\
\hline Evet & 214 & 73.8 \\
\hline Hayır & 76 & 26.2 \\
\hline Toplam & $\mathbf{2 9 0}$ & $\mathbf{1 0 0}$ \\
\hline
\end{tabular}

Yukarıdaki tablo incelendiğinde öğretmenlerin çoğunun "akıllı telefonlarındaki interneti sürekli açk tuttukları" tespit edilmiştir.

Tablo 6. Akıllı Telefonları Günlük Kullanım Süresi

\begin{tabular}{lll}
\hline Günlük Kullanim Süresi & $\mathbf{N}$ & $\mathbf{\%}$ \\
\hline 1-2 saat & 20 & 7.0 \\
\hline 3-4 saat & 76 & 26.2 \\
\hline 5-6 saat & 59 & 20.3 \\
\hline 6 saat ve fazlasi & 135 & 46.5 \\
\hline Toplam & $\mathbf{2 9 0}$ & $\mathbf{1 0 0}$ \\
\hline
\end{tabular}

Yukarıdaki tablo incelendiğinde öğretmenlerin çoğunun akıllı telefonlarında geçirdikleri vakitler sıklıkla "6 saat ve fazlası" olarak saptanmıştır. 
Tablo 7. Akıllı Telefonları Kontrol Aralı̆̆ı

\begin{tabular}{|c|c|c|}
\hline Kontrol Aralı̆ğ & $\mathbf{N}$ & $\%$ \\
\hline $1 \mathrm{dk}$ bir & 2 & 17 \\
\hline $2 \mathrm{dk} \mathrm{bir}$ & 8 & 12.8 \\
\hline $5 \mathrm{dk} \mathrm{bir}$ & 10 & 3.4 \\
\hline $10 \mathrm{dk} \mathrm{bir}$ & 25 & 8.6 \\
\hline $15 \mathrm{dk} \mathrm{bir}$ & 18 & 6.2 \\
\hline $20 \mathrm{dk} \mathrm{bir}$ & 21 & 7.2 \\
\hline $25 \mathrm{dk} \mathrm{bir}$ & 2 & .7 \\
\hline $30 \mathrm{dk} \mathrm{bir}$ & 95 & 32.8 \\
\hline $40 \mathrm{dk} \mathrm{bir}$ & 2 & .7 \\
\hline $45 \mathrm{dk} \mathrm{bir}$ & 11 & 3.8 \\
\hline $60 \mathrm{dk} \mathrm{bir}$ & 67 & 23.1 \\
\hline $80 \mathrm{dk} \mathrm{bir}$ & 2 & .7 \\
\hline $90 \mathrm{dk} \mathrm{bir}$ & 4 & 1.4 \\
\hline $100 \mathrm{dk}$ bir & 4 & 1.4 \\
\hline 2 saat bir & 14 & 4.8 \\
\hline 3 saat bir & 1 & .3 \\
\hline 4 saat bir & 2 & .7 \\
\hline 4 saat ve fazlası & 2 & .7 \\
\hline Toplam & 290 & 100 \\
\hline
\end{tabular}

Yukarıdaki tablo incelendiğinde öğretmenlerin akıllı telefonlarını kontrol aralığ1 sıklıkla "30 dk'da bir" olarak tespit edilmiştir.

Tablo 8. Akıllı Telefonu Unutunca Panik Olma Durumu

\begin{tabular}{lll}
\hline Panik Durumu & N & $\%$ \\
\hline Evet & 172 & 59.3 \\
\hline Hayir & 118 & 40.7 \\
\hline Toplam & 290 & 100 \\
\hline
\end{tabular}

Tablo 8 incelendiğinde öğretmenlerin çoğunun akıllı telefonlarını evde veya işyerlerinde unuttuklarında "panik oldukları" tespit edilmiştir.

Tablo 9. Araç Kullanırken Akıllı Telefon Kullanma Durumu

\begin{tabular}{lll}
\hline Araç Kullanırken Akıllı Telefon Kullanma & $\mathbf{N}$ & \% \\
\hline Evet & 88 & 30.3 \\
\hline Hayır & 202 & 60.7 \\
\hline Toplam & $\mathbf{2 9 0}$ & $\mathbf{1 0 0}$ \\
\hline
\end{tabular}

Yukarıdaki tablo incelendiğinde öğretmenlerin çoğunun araç kullanırken akıllı telefonlarını kullanmadıkları tespit edilmiştir. Bu sonuca rağmen, araç kullanırken akıllı telefonların kullanan öğretmenlerin sayısı da dikkat çekmektedir. 
Tablo 10. Araç Kullanırken Metin-Mesaj-E-mail Yazma

\begin{tabular}{lll}
\hline Araç Kullanırken Metin-Mesaj-E mail Yazma & $\mathbf{N}$ & $\mathbf{\%}$ \\
\hline Evet & 16 & 5.5 \\
\hline Hayır & 274 & 94.5 \\
\hline Toplam & $\mathbf{2 9 0}$ & $\mathbf{1 0 0}$ \\
\hline
\end{tabular}

Yukarıdaki tablo incelendiğinde öğretmenlerin çoğunun araç kullanırken metin-mesaj-e mail yazmadıkları tespit edilmiştir.

Tablo 11. Akıllı Telefonlan Kullanım Amaçlan

\begin{tabular}{lll}
\hline Kullanim Amaçları & $\mathbf{N}$ & $\mathbf{\%}$ \\
\hline sosyal medya & 129 & 22.1 \\
\hline e-posta & 62 & 43.8 \\
\hline sohbet & 14 & 4.8 \\
\hline mesajlaşma & 44 & 6.6 \\
\hline haber okuma & 6 & 2.1 \\
\hline oyun oynama & 16 & 5.5 \\
\hline film izleme & 5 & 1.4 \\
\hline müzik dinleme & 9 & 3.1 \\
\hline diğer & 5 & 1.4 \\
\hline Toplam & $\mathbf{2 9 0}$ & $\mathbf{1 0 0}$ \\
\hline
\end{tabular}

Yukarıdaki tablo incelendiğinde araştırmaya katılan öğretmenlerin akıllı telefonlarını yoğunlukla "sosyal medya" için kullandıkları tespit edilmiştir.

\section{Bulgular}

Ölçek maddelerine ilişkin analiz sonuçlarına (ortalama $(\mathrm{x})$ ve standart sapma (sd) değerleri olmak üzere) Tablo 12.'de yer verilmiştir.

Tablo 12. Ölçek Maddeleri Ortalama ve Standart Sapma Değerleri

\begin{tabular}{lccc}
\hline Madde ve Faktörler & $\bar{X}$ & SD \\
\hline M22. Akıllı telefonumu az kullandığım zaman kendimi daha az hoşnut hissediyorum. & 3,40 & 1,38 \\
\hline $\begin{array}{l}\text { M23. Kendimi daha hoşnut hissetmem için akıllı telefonumu kullanmaya daha fazla vakit } \\
\text { ayırmalıyım. }\end{array}$ & 3,04 & 1,73 \\
\hline M24. Akıllı telefonumu kullanmayı bıraktığımda karamsar ve huzursuz oluyorum. & 2,51 & 1,50 \\
\hline M25. Akıllı telefonumu kullanmayı bıraktı̆̆ımda duygusal açıdan çok zorlanıorum. & 2,54 & 1,47 \\
\hline M26. Akıllı telefonumu kullanmaya harcadığım zaman, diğer önemli işlerime engel oluyor. & 3,04 & 1,44 \\
\hline $\begin{array}{l}\text { M27. Geçmişi düşündüğümde akıllı telefonumla geçirdiğim zamann normal olmadığını dü- } \\
\text { şünüyorum. }\end{array}$ & 3,55 & 1,42 \\
\hline M28. Akıllı telefonumla çok fazla zaman harcadığıma inanıyorum. & 3,46 & 1,41 \\
\hline M29. İnsanlar (ailem, arkadaşlarım) akıllı telefonumda çok fazla zaman harcadığımı söylüyor. & 2,66 & 1,64 \\
\hline
\end{tabular}




\begin{tabular}{|c|c|c|}
\hline $\begin{array}{l}\text { M30. Akıllı telefonumu kullanmadığım zamanlarda, o an ya da bir sonraki sefer kullanmayı } \\
\text { düşünüyorum. }\end{array}$ & 3,14 & 1,62 \\
\hline M31. Çağrı ya da mesaj almadığım zamanlarda kaygılı hissediyorum. & 3,18 & 1,55 \\
\hline $\begin{array}{l}\text { M32. Akıllı telefonumu kullanırken yanımda bulunan kişileri (ailem, arkadaşlarım) görmez- } \\
\text { den geldiğimi fark ediyorum. }\end{array}$ & 3,65 & 1,63 \\
\hline M33. İs ya da okulla ilgili çalışmalar yapmam gerektiğinde akıllı telefonumu kullanırım. & 3,17 & 1,47 \\
\hline M34. Uyumam gerektiğini bildiğim hâlde akıllı telefonumu kullanmaya devam ediyorum. & 3,39 & 1,76 \\
\hline $\begin{array}{l}\text { M35. Akıllı telefonumu kullanmayı bıraktığımda hayatım etkilendiğini zannedip onu tekrar } \\
\text { kullanmaya devam ediyorum. }\end{array}$ & 3,45 & $\overline{1,84}$ \\
\hline M36. Akıllı telefonumu çok kullandığım için iş yeri ya da okulda sorun yaşıyorum. & 2,62 & 1,62 \\
\hline $\begin{array}{l}\text { M37. Benim için önemli olan ve benimle zaman geçirmek isteyen insanlar yerine akıllı telefo- } \\
\text { numla vakit geçiriyorum. }\end{array}$ & 3,29 & $\overline{1,41}$ \\
\hline $\begin{array}{l}\text { M38. Akıllı telefon kullanmanın tehlikeli olduğunu bildiğim hâlde onu kullanmaya devam } \\
\text { ediyorum. }\end{array}$ & 2,89 & 1,74 \\
\hline M39. Ak1llı telefonumu kullanırken neredeyse bir kazaya neden oluyordum. & 3,39 & $\overline{1,48}$ \\
\hline M40. Akıllı telefonun ilişkilerimde sorunlara neden olduğunu düşünüyorum. & 3,22 & 1,76 \\
\hline 441. Biri bana & 3,29 & 1,71 \\
\hline Genel Ortalama & 3,14 & 1,57 \\
\hline
\end{tabular}

20 madde ve 3 boyut için ortalamanın 3,65 ile 2,00 değerleri arasında değiştiği ortaya konulmuştur. Sonuçların yorumlanmasında kullanılan puan s1nirlar1; Kesinlikle Katılmıyorum: 1,00-1,79; Katılmiyorum: 1,80-2,59; Karars1zım: 2,60-3,39; Katıliyorum: 3,40-4,19; Kesinlikle Katıliyorum: 4,20-5,00 (Büyüköztürk, 2013) değerleri arasında kabul görülmüştür. Bu bağlamda ilgili ölçek için tüm maddelerin genel ortalaması 2,82 olduğundan öğretmenlerin yanıtlarının genel olarak "Kararsızım" seçeneği üzerinde yoğunlaştığı anlaşlmaktadır.

20 madde içerisinde en yüksek ortalamaya sahip olan ölçek maddesi: "Akıllı telefonumu kullanırken yanımda bulunan kişileri (ailem, arkadaşlarım) görmezden geldiğimi fark ediyorum" olmakla birlikte en düşük ortalamaya sahip maddenin ise; "Akıllı telefonumu kullanmayı bıraktığımda karamsar ve huzursuz oluyorum" olduğu saptanmıştır.

\section{Öğretmenlerin Demografik Özelliklerinin Nomofobi Düzeylerine Etkisi}

Öğretmenlerin demografik özelliklerinin, nomofobi düzeylerine anlamlı bir etki oluşturup oluşturmadığını tespit etmek üzere Tek Yönlü Anova testinden yararlanılmıştır. Tek Yönlü Anova testi; üç ya da daha çok düzeyi bulunan bir bağımsız değişkenin, bir sürekli bağımlı değişken üzerindeki etkisini belirlemeye yönelik yapılan bir testtir (Büyüköztürk, 2013). 
Tablo 13. Cinsiyete Göre Etkisi Tek Yönlü Anova Testi Sonucu

\begin{tabular}{lllllll}
\hline $\begin{array}{l}\text { Varyansın } \\
\text { Kaynağı }\end{array}$ & $\begin{array}{l}\text { Kareler } \\
\text { Toplamı }\end{array}$ & sd & $\begin{array}{l}\text { Kareler } \\
\text { Ortalaması }\end{array}$ & F & p & $\begin{array}{l}\text { Anlamlı } \\
\text { Fark }\end{array}$ \\
\hline $\begin{array}{l}\text { Gruplar arası } \\
\begin{array}{l}\text { Gruplar içi } \\
\text { Toplam }\end{array}\end{array}$ & $\begin{array}{l}005 \\
120,730\end{array}$ & 1 &, 005 & & & \\
\hline
\end{tabular}

Yukarıdaki tablo incelendiğinde yapılan tek yönlü anova testi sonucuna göre; öğretmenlerin nomofobi düzeylerinin cinsiyete göre anlamlı bir etkisinin olmadığı ortaya konulmuştur ( $p>0.05)$.

Tablo 14.1. Yaşa Göre Etkisi Tek Yönlü Anova Testi Sonucu

\begin{tabular}{lllllll}
\hline Varyansın Kaynağı & Kareler Toplamı & sd & $\begin{array}{l}\text { Kareler } \\
\text { Ortalaması }\end{array}$ & F & p & Anlamlı Fark \\
\hline Gruplar arası & 5,246 & 4 & 1,311 & & & \\
Gruplar içi & 115,489 & 285 & & 3,326 &, 013 & Anlamlı fark vardır. \\
Toplam & $\mathbf{1 2 0 , 7 3 5}$ & $\mathbf{2 8 9}$ &, 405 & & & \\
\hline
\end{tabular}

Yukarıdaki tablo incelendiğinde yapılan tek yönlü anova testi sonucuna göre; öğretmenlerin nomofobi düzeylerinin yaşa göre anlamlı bir etkisinin olduğu ortaya konulmuştur $(\mathrm{p}<0.05)$. Hangi alt grupların diğerinden farklı olduğunu tespit etmek amacıyla Post Hoc Testlerinden yararlanılmıştır. Böylece düzeyler arasındaki fark incelenmiştir. Araştırmada Post Hoc testlerinden Scheffe tercih edilmiştir. Scheffe testi; yalnızca çift karşılaştırmalar için düzeltme yapmaz, aynı zamanda belirlenen her türlü olası karşılaştırmalar için de analiz yapan bir testtir (Can, 2016). Scheffe testinin alt gruplar arasındaki karşılaştırmalı sonuçları Tablo 14.1'de sunulmuştur.

Tablo 14.2.. Alt Gruplar Arasındaki Karşılaştırmalı Sonuçlar Scheffe Testi

\begin{tabular}{llllll}
\hline & Yaş & Sira Farki & S & p & \\
\hline $\mathbf{2 1 - 2 5}$ & $26-30$ &, 40710 &, 16705 &, 329 & \\
\hline & $30-35$ &, 40918 &, 16582 &, 329 & Anlamlı fark vardır. \\
\hline & $35-40$ &, 53394 &, 17508 &, 095 & \\
\hline & $40+$ &, $52748^{*}$ &, 15357 &, 003 & \\
\hline
\end{tabular}

Tablo 15 incelendiğinde Scheffe testi sonuçlarına göre; yaş alt grupları karşılaştırıldığında 21-25 ve 40+ yaş grubu arasında anlamlı bir farkın olduğu ortaya konulmuştur $(\mathrm{p}<0.05)$. 
Tablo 15. Eğitim Durumuna Göre Etkisi Tek Yönlü Anova Testi Sonucu

\begin{tabular}{lllllll}
\hline Varyansın Kaynağı & Kareler Toplamı & sd & $\begin{array}{l}\text { Kareler } \\
\text { Ortalaması }\end{array}$ & F & p & Anlamlı Fark \\
\hline Gruplar arası & 1,154 & 2 &, 577 & & & \\
$\begin{array}{l}\text { Gruplar içi } \\
\text { Toplam }\end{array}$ & 119,581 & 287 & & & & \\
\hline
\end{tabular}

Yukarıdaki tablo incelendiğinde yapılan tek yönlü anova testi sonucuna göre; öğretmenlerin nomofobi düzeylerinin eğitim durumuna göre anlamlı bir etkisinin olmadığı ortaya konulmuştur ( $p>0.05$ ).

Tablo 16. Branşa Göre Etkisi Tek Yönlü Anova Testi Sonucu

\begin{tabular}{lllllll}
\hline Varyansın Kaynağı & Kareler Toplamı & sd & $\begin{array}{l}\text { Kareler } \\
\text { Ortalaması }\end{array}$ & F & p & Anlamlı Fark \\
\hline Gruplar arası & 15,336 & 8 & 1,917 & & & \\
Gruplar içi & 105,399 & 281 & & 5,111 &, 061 & Anlamlı fark yoktur. \\
Toplam & $\mathbf{1 2 0 , 7 3 5}$ & $\mathbf{2 8 9}$ &, 375 & & & \\
\hline
\end{tabular}

Yukarıdaki tablo incelendiğinde yapılan tek yönlü anova testi sonucuna göre; öğretmenlerin nomofobi düzeylerinin branşa göre anlamlı bir etkisinin olmadığ 1 ortaya konulmuştur $(\mathrm{p}>0.05)$.

Tablo 17. Çalışılan Kuruma Göre Tek Yönlü Anova Testi Sonucu

\begin{tabular}{|c|c|c|c|c|c|c|}
\hline $\begin{array}{l}\text { Varyansın } \\
\text { Kaynağ1 }\end{array}$ & $\begin{array}{l}\text { Kareler } \\
\text { Toplamı }\end{array}$ & sd & $\begin{array}{l}\text { Kareler } \\
\text { Ortalaması }\end{array}$ & $\mathbf{F}$ & $\mathrm{p}$ & $\begin{array}{l}\text { Anlamlı } \\
\text { Fark }\end{array}$ \\
\hline Gruplar arası & 358 & 1 & ,358 & & & Anlamli \\
\hline Gruplar içi & 120,377 & 288 & & 857 & ,355 & fark yoktur. \\
\hline Toplam & 120,735 & 289 & ,418 & & & \\
\hline
\end{tabular}

Tablo 17 incelendiğinde yapılan tek yönlü anova testi sonucuna göre; öğretmenlerin nomofobi düzeylerinin çalıştıkları kuruma (kamu veya özel) göre anlamlı bir etkisinin olmadığı ortaya konulmuştur ( $\mathrm{p}>0.05)$.

Tablo 18.1. Çalıșılan Kademeye Göre Tek Yönlü Anova Testi Sonucu

\begin{tabular}{llllccl}
\hline $\begin{array}{l}\text { Varyansın } \\
\text { Kaynağı }\end{array}$ & $\begin{array}{l}\text { Kareler } \\
\text { Toplamı }\end{array}$ & sd & $\begin{array}{l}\text { Kareler } \\
\text { Ortalaması }\end{array}$ & F & p & $\begin{array}{l}\text { Anlamlı } \\
\text { Fark }\end{array}$ \\
\hline $\begin{array}{l}\text { Gruplar arası } \\
\text { Gruplar içi }\end{array}$ & 9,997 & 4 & 2,499 & & & Anlamlı \\
Toplam & 110,738 & 285 & & 6,432 & \multirow{2}{*}{000} & fark vardır. \\
\hline
\end{tabular}

Tablo 18.1 incelendiğinde yapılan tek yönlü anova testi sonucuna göre; öğretmenlerin nomofobi düzeylerinin çalıştıkları kademeye göre anlamlı bir 
etkisinin olduğu ortaya konulmuştur ( $\mathrm{p}<0.05)$. Hangi alt grupların diğerinden farklı olduğunu tespit etmek amaciyla Post Hoc Testlerinden yararlanılmıştır. Böylece düzeyler arasındaki fark incelenmiştir.

Tablo 18.2. Alt Gruplar Arasındaki Karşılaştırmalı Sonuçlar Scheffe Testi

\begin{tabular}{llcccc}
\hline & Kademe & Sıra Farkı & S & p & \\
\hline \multirow{4}{*}{ Okul öncesi } & İlköğretim & 1,02976 &, 20908 &, 000 & \\
& Ortaokul &, 83889 &, 20713 &, 003 & Anlamlı fark var \\
& Lise &, 80836 &, 20693 &, 005 & \\
& Üniversite &, 81905 &, 32189 &, 170 & \\
\hline
\end{tabular}

Tablo 18.2. incelendiğinde Scheffe testi sonuçlarına göre; kademe alt grupları karşılaştırıldığında okul öncesi-ilköğretim; okul öncesi-ortaokul ve okul öncesi-lise kademe grupları arasında anlamlı bir farkın olduğu ortaya konulmuştur $(\mathrm{p}<0.05)$.

Tablo 19. Mesleki Kıdeme Göre Tek Yönlü Anova Testi Sonucu

\begin{tabular}{lllllll}
\hline $\begin{array}{l}\text { Varyansın } \\
\text { Kaynağı }\end{array}$ & Kareler Toplamı & sd & $\begin{array}{l}\text { Kareler } \\
\text { Ortalaması }\end{array}$ & F & p & Anlamlı Fark \\
\hline $\begin{array}{l}\text { Gruplar arası } \\
\text { Gruplar içi }\end{array}$ & 5,700 & 5 & 1,140 & & & \\
Toplam & 106,699 & 284 & & 2,981 &, 012 & $\begin{array}{l}\text { Anlamlı fark } \\
\text { yoktur. }\end{array}$ \\
\hline
\end{tabular}

Yapılan tek yönlü anova testi sonucuna göre; öğretmenlerin nomofobi düzeylerinin mesleki kıdemlerine göre anlamlı bir etkisinin olmadığı ortaya konulmuştur ( $\mathrm{p}>0.05)$.

Tablo 20. Medeni Duruma Göre Tek Yönlü Anova Testi Sonucu

\begin{tabular}{lllllll}
\hline Varyansın Kaynağı & Kareler Toplamı & sd & $\begin{array}{l}\text { Kareler } \\
\text { Ortalaması }\end{array}$ & F & p & Anlamlı Fark \\
\hline Gruplar arası &, 112 & 1 &, 112 & & & \\
Gruplar içi & 120,621 & 288 & & 265 &, 607 & Anlamlı fark yoktur. \\
Toplam & $\mathbf{1 2 0 , 7 3 5}$ & $\mathbf{2 8 9}$ &, 422 &, 265 \\
\hline
\end{tabular}

Yapılan tek yönlü anova testi sonucuna göre; öğretmenlerin nomofobi düzeylerinin medeni durumlarına göre anlamlı bir etkisinin olmadığı ortaya konulmuştur ( $p>0.05$ ). 


\section{Öğretmenlerin Akıllı Telefon Kullanım Alışkanlıklarının Nomofobi Düzeylerine Etkisi}

Öğretmenlerin nomofobi düzeylerinin akıllı telefon kullanım alışkanlıklarına (akıllı telefon kullanma yılı, şarj etme aralığı, akıllı telefonu kontrol etme aralığı) göre farklılaşıp farklılaşmadığını belirlemek için tek yönlü anova testi uygulanmıştır. Bu analizlere ait sonuçlar aşağıda verilmiştir.

Tablo 21. Akıllı Telefon Kullanım Yılına Göre

\begin{tabular}{|c|c|c|c|c|c|c|c|}
\hline $\begin{array}{l}\text { Varyansın } \\
\text { Kaynağı }\end{array}$ & $\begin{array}{l}\text { Kareler } \\
\text { lamı }\end{array}$ & Top- & sd & $\begin{array}{l}\text { Kareler } \\
\text { Ortalaması }\end{array}$ & F & $\mathrm{p}$ & Anlamlı Fark \\
\hline Gruplar arası & 5,099 & & 4 & 1,275 & & & Anlamlı fark \\
\hline Gruplar içi & 115,636 & & 285 & & 3,142 & ,015 & yoktur. \\
\hline Toplam & 120,735 & & 289 & ,406 & & & \\
\hline
\end{tabular}

Yukarıdaki tablo incelendiğinde yapılan tek yönlü anova testi sonucuna göre; öğretmenlerin nomofobi düzeylerinin akıllı telefon kullanım yılına göre anlamlı bir etkisinin olmadığı ortaya konulmuştur $(\mathrm{p}>0.05)$.

Tablo 22. Akıllı Telefon Şarj Etme Aralı̆̆ına Göre

\begin{tabular}{|c|c|c|c|c|c|c|}
\hline $\begin{array}{l}\text { Varyansın } \\
\text { Kaynağı }\end{array}$ & $\begin{array}{l}\text { Kareler } \\
\text { Toplamı }\end{array}$ & sd & $\begin{array}{l}\text { Kareler } \\
\text { Ortalaması }\end{array}$ & F & $p$ & $\begin{array}{l}\text { Anlamlı } \\
\text { Fark }\end{array}$ \\
\hline Gruplar arası & 12,108 & 3 & 4,036 & & & Anlamlı \\
\hline Gruplar içi & 108,627 & 286 & & 10,626 &, 000 & fark \\
\hline Toplam & 120,735 & 289 &, 380 & & & vardır. \\
\hline
\end{tabular}

Yapılan tek yönlü anova testi sonucuna göre; öğretmenlerin nomofobi düzeylerinin akıllı telefonları şarj etme aralığına göre anlamlı bir etkisinin olduğu ortaya konulmuştur $(\mathrm{p}<0.05)$.

Tablo 23. Akıllı Telefon Kontrol Etme Aralı̆̆ına Göre

\begin{tabular}{|c|c|c|c|c|c|c|}
\hline $\begin{array}{l}\text { Varyansın } \\
\text { Kaynağı } \\
\end{array}$ & $\begin{array}{l}\text { Kareler } \\
\text { Toplamı } \\
\end{array}$ & sd & $\begin{array}{l}\text { Kareler } \\
\text { Ortalaması } \\
\end{array}$ & $\mathbf{F}$ & $p$ & $\begin{array}{l}\text { Anlamlı } \\
\text { Fark }\end{array}$ \\
\hline Gruplar arası & 23,106 & 18 & 1,284 & & & \\
\hline Gruplar içi & 97,628 & 271 & & 3,563 & ,000 & Anlamlı \\
\hline Toplam & 120,735 & 289 & ,360 & & & fark vardır. \\
\hline
\end{tabular}

Yapılan tek yönlü anova testi sonucuna göre; öğretmenlerin nomofobi düzeylerinin akıllı telefonlan kontrol etme aralığına göre anlamlı bir etkisinin olduğu ortaya konulmuştur ( $\mathrm{p}<0.05)$. 
Tablo 24. Akıllı Telefonu Unutunca Panik Olma Durumu

\begin{tabular}{lllllll}
\hline $\begin{array}{l}\text { Varyansın } \\
\text { Kaynağı }\end{array}$ & $\begin{array}{l}\text { Kareler } \\
\text { Toplamı }\end{array}$ & sd & $\begin{array}{l}\text { Kareler } \\
\text { Ortalaması }\end{array}$ & F & p & $\begin{array}{l}\text { Anlamlı } \\
\text { Fark }\end{array}$ \\
\hline $\begin{array}{l}\text { Gruplar arası } \\
\text { Gruplar içi }\end{array}$ & 21,501 & 1 & 21,501 & & & Anlamlı \\
Toplam & 99,234 & 288 & & 62,401 & \multirow{2}{*}{000} & $\begin{array}{l}\text { fark } \\
\text { vardır. }\end{array}$ \\
\hline
\end{tabular}

Yukarıdaki tabloda yapılan tek yönlü anova testi sonucuna göre; öğretmenlerin nomofobi düzeylerinin akıllı telefonlar unutulduğunda panik olma durumuna göre anlamlı bir etkisinin olduğu ortaya konulmuştur $(\mathrm{p}<0.05)$.

Akıllı Telefonu Şarj Etme Aralı̆̆ ile Nomofobi Düzeyi Arasındaki İlişki Pearson Korelasyon Katsayısı Sonucu

Tablo 25. Akıllı Telefonlan Şarj Etme Aralığı ile Nomofobi Düzeyi Arasındaki İlişki

\begin{tabular}{lccc}
\hline & $\mathrm{N}$ & $\mathrm{R}$ & $\mathrm{p}$ \\
\hline Nomofobi Düzeyi & 290 & 480 &, 000 \\
& & & \\
\hline
\end{tabular}

Yukarıdaki tabloda görüldüğü üzere öğretmenlerin nomofobi düzeyleri ile akıllı telefonlarını şarj etme aralıkları arasında pozitif ve anlamlı bir ilişki saptanmıştır $(\mathrm{r}=, 480$ ve $\mathrm{p}<0,01)$.

Akıllı Telefonu Kontrol Etme Aralı̆̆ı ile Nomofobi Düzeyi Arasındaki İlişki Pearson Korelasyon Katsayısı Sonucu

Tablo 27. Kontrol Etme Aralığı ile Nomofobi Düzeyi Arasındaki İlişki

\begin{tabular}{lccc}
\hline & N & R & p \\
\hline Nomofobi Düzeyi & 290 & 261 &, 000 \\
Panik Olma Durumu & & & \\
\hline
\end{tabular}

Yukarıdaki tabloda görüldüğü üzere öğretmenlerin nomofobi düzeyleri ile akıllı telefonların kontrol etme aralıkları arasında pozitif ve anlamlı bir ilişki saptanmıştır $(r=, 261$ ve $p<0,01)$. 


\section{Akilh Telefonu Unutunca Panik Olma Durumu ile Nomofobi Düzeyi Arasındaki İlişki Pearson Korelasyon Katsayısı Sonucu}

Tablo 28. Panik Olma Durumu ile Nomofobi Düzeyi Arasındaki İlişki

\begin{tabular}{lccc}
\hline & N & R & p \\
\hline Nomofobi Düzeyi & 290 &, 863 &, 000 \\
Panik Olma Durumu & & & \\
\hline
\end{tabular}

Yukarıdaki tabloda görüldüğü üzere öğretmenlerin nomofobi düzeyleri ile akıllı telefonlarını kontrol etme aralıkları arasında yüksek düzeyde pozitif ve anlamlı bir ilişki saptanmıştır $(\mathrm{r}=, 863$ ve $\mathrm{p}<0,01)$.

\section{Sonuç ve Tartışma}

Öğretmenlerin nomofobi düzeylerinin belirlenmeye çalışıldığı bu araştırmada, örnekleme yöntemi olarak uygun örnekleme yönteminden yararlanılmiş ve bu bağlamda Sakarya ilinde kamu ve özel eğitim kurum ve kuruluşlarında görev yapan 290 öğretmen ile çalışılmıştır. Araştırma sonuçlarına aşağıda yer verilmiştir:

Bu araştırmada, öğretmenlerin nomofobi düzeylerinin demografik özelliklerine ve akıllı telefon kullanım alışkanlıklarına göre ne gibi değişiklikler gösterdiği belirlenmeye çalışılmıştır. Buna göre öğretmenlerin en çok kullandıkları sosyal medya aracının "YouTube" olduğu ortaya konulmuştur. Birbiri (2013), araştırmasında ise öğretmenlerin en çok kullandıkları sosyal medya aracının Facebook olduğunu tespit etmiştir. Öğretmenlerin akıllı telefon kullanım yılının yoğunlukla "6 yıl ve daha fazlası" olduğu saptanmıştır. Benzer bir sonuç olarak Sırakaya (2018), araştırmasında ön lisans öğrencilerinin de akıllı telefon kullanım yoğunluklarının 5 yıl ve üzeri olduğunu ortaya koymuşlardır. Öğretmenlerin akıllı telefonlarını şarj etme süreleri yoğunlukla "4 saat ve fazlası" olarak tespit edilmiştir. Bu durumun akıllı telefonları kullanım sıklığıyla paralellik gösterdiği düşünülmektedir. Akıllı telefonun şarjının tükenmesinin nomofobik bireylerde endişe yaratan bir durum olduğu araştırmalarda vurgulanmıştır (Bragazzi ve Pente, 2014; Gezgin ve Çakır, 2016; Pavithra ve Madhukumar, 2015).Öğretmenlerin sahip oldukları akıllı telefonların adeti sıklıkla "1" olarak tespit edilip bunun yanı sıra 2' den fazla akıllı telefona sahip olan öğretmenlerin de var olduğu saptanmıştır. 
Araştırmada, öğretmenlerin çoğunluğunun gün içerisinde akıllı telefonlarındaki interneti sürekli açık tuttukları tespit edilmiştir. Bu sonucun nomofobiklik adına oldukça önemli olduğu düşünülmektedir. Bir diğer sonuç; öğretmenlerin akıllı telefonlarında geçirdikleri günlük vakit yoğunlukla "6 saat ve üzeri" olarak tespit edilmiştir. Soni ve arkadaşlarının yapmış oldukları araştırmaya göre (2017) gençlerin akıllı telefonda önemli bir zaman harcadıkları ve böylece bağımlılık eğilimlerinin arttığ tespit edilmiştir. Akıllı telefonları kontrol aralığının ise yoğunlukla "30 dk'da bir" olduğu belirlenmiştir. S1rakaya ise bu kontrol süresinin sıklıkla 1-19 dk arası olduğunu ortaya koymuştur. Ortaya çıkan bu sonuç literatürdeki birçok çalışma tarafından da desteklenmektedir. Yapılan çalışmalarda akıllı telefon kullanıcılarının çoğunluğunun geceleri dahi telefonlarını kapatmadıkları saptanmıştır (Dixit ve diğerleri, 2010; Kaur ve diğerleri 2015; King ve diğerleri 2013). Hoşgör, Tandoğan ve Hoşgör (2017) ise çalışmasında, sağlık personellerinin çoğunun uyanır uyanmaz ve gece yatmadan önce akıllı telefonlarını kontrol ettiklerini tespit etmiştir. Bireylerin bu denli sıklıkla akıllı telefonlarını kontrol etme isteği duymaları kendilerine gelebilecek bildirimlere önem verdikleri şeklinde yorumlanabilir. Elde edilen bu bulgunun derinlemesine incelenmesi nomofobikliğin tespiti adına önem taşımaktadır.

Elde edilen bir diğer bulgu, öğretmenlerin çoğunun akıllı telefonlarını evde veya işyerlerinde unuttuklarında "panik durumu" yaşamalarıdır. Benzer bir sonuç olarak Sharma ve diğerleri (2015) tarafından yapılan araştırmada tıp fakültesi öğrencilerinden oluşan katılımciların yaklaşık \%83'ünün mobil cihazlarına erişemedikleri durumda panik atak geçirecekleri saptanmıştır.

Araştırmada, öğretmenlerin çoğunluğunun "araçlarında da akıllı telefonları kullandıkları"; buna rağmen "araçlarında metin-mesaj-email yazıp göndermedikleri" sonucu ortaya konulmuştur. Öğretmenlerin akıllı telefonlarını daha çok "sosyal medya" için kullandıkları sonucu da elde edilen bir diğer sonuçtur.

$\mathrm{Bu}$ araştırmada, öğretmenlerin nomofobiklik düzeylerini belirlemek adına veri toplama aracı olarak Merlo, Stone ve Bibbey (2013) tarafindan geliştirilen problemli akıllı telefon kullanımı ve ön psikometrik özellikleri ölçeğinden yararlanılmıştır. Ölçek 2 boyuttan oluşup toplamda 20 maddedir. Sonuç olarak 20 madde içerisinde en yüksek ortalamaya sahip olan ölçek mad- 
desi: "Akıllı telefonumu kullanırken yanımda bulunan kişileri (ailem, arkadaşlarım) görmezden geldiğimi fark ediyorum" olmakla birlikte en düşük ortalamaya sahip maddenin ise; "Akıllı telefonumu kullanmayı bıraktığımda karamsar ve huzursuz oluyorum" olduğu saptanmıştır. Ölçek için tüm maddelerin genel ortalaması 2,82 olarak saptanmış ve bu bağlamda öğretmenlerin yanıtlarının genel olarak "Kararsızım" seçeneği üzerinde yoğunlaştığı tespit edilmiştir.

Araştırmada öğretmenlerin nomofobi düzeylerinin demografik özelliklerine göre anlamlılık gösterip göstermediği ortaya konulmaya çalışılmış bu bağlamda yapılan ilgili analizlere göre; öğretmenlerin cinsiyet, eğitim durumu, branş, çalışılan kurum ve mesleki kıdemleri ile nomofobi düzeyleri arasında anlamlı bir farklılık olmadığı ortaya konulmuştur. Alan yazın incelendiğinde Schifferstein vd. (2006) ve Lee vd. (2014) yaptıkları araştırmada, nomofobi düzeyinin kız öğrenciler açısından anlamlı bir farklılık gösterdiğini; Kwon vd. (2013) ve Takao vd. (2009) ise nomofobi düzeyinin erkek öğrenciler açısından anlamlılık gösterdiğini çalışmalarında ortaya koymuşlardır. Araştırma sonucuna benzer olarak Dixit vd. (2010), araştırmalarında sağlık bilimleri öğrencilerinin nomofobi düzeylerinin cinsiyet değişkeni açısından anlamlılık göstermediğini saptamışlardır. Benzer şekilde; Uysal vd. (2016) tarafından 265 öğrenci, Pavithra vd. (2015) tarafından 200 öğrenci üzerinde yapılan olan çalışmalarda da cinsiyet değişkeni ile nomofobi düzeyi arasında anlamlı bir ilişki tespit edilmemiştir.

Araştırmada öğretmenlerin nomofobi düzeylerinin yaş değişkeni açısından anlamlı farklılık gösterdiği bu bağlamda 21-25 yaş arasındaki öğretmenlerin nomofobi düzeylerinin 40 yaş ve üzeri öğretmenlerin nomofobi düzeyinden anlamlı derecede yüksek olduğu ortaya konulmuştur. Bu sonuca benzer olarak Bragazzi ve Del Puente (2014) araştırmalarında ergenlerde nomofobi düzeyinin daha yüksek olduğu ve bu yaş aralığını 25-34 yaş grubu ile 55 yaş üstünün izlediğini saptamışlardır. Yılmaz, Köse ve Doğru (2018) de yaş ile nomofobi arasında ters yönlü ve anlamlı bir ilişki olduğunu araştırmalarında ortaya koymuşlardır.

Araştırmada öğretmenlerin çalıştıkları kademelerle nomofobi düzeyleri arasında anlamlı bir ilişkinin olduğu saptanmış; bu bağlamda okul öncesi kademesindeki öğretmenlerin nomofobi düzeylerinin ilkokul-ortaokul ve lise kademelerindeki öğretmenlerin nomofobi düzeyinden anlamlı derecede yüksek olduğu belirlenmiştir. Gezgin vd., (2019) araştırmalarında 608 okul 
öncesi öğretmenleri ile çalışmışlar, sonuç olarak akıllı telefonlarındaki mobil interneti sosyal ağlara girme, fotoğraf çekme ve düzenleme, internette gezinme (sörf yapma) amaciyla kullanan okul öncesi öğretmenlerinin nomofobi düzeylerinin anlamlı farklılık oluşturduğunu tespit etmişlerdir.

Araştırmada öğretmenlerin nomofobi düzeylerinin akıllı telefon kullanım alışkanlıklarına göre anlamlılık gösterip göstermediği ortaya konulmaya çalışılmış bu bağlamda yapılan analizlere göre; akıllı telefon kullanım yılına göre nomofobi düzeylerinde anlamlı fark görülmezken; akıllı telefonlarını şarj etme ve kontrol etme aralığı ile akıllı telefonlarını unutunca panik olma durumları arasında anlamlı bir fark olduğu saptanmıştır. Bu değişkenler arasındaki ilişkiyi belirlemek üzere Pearson Korelasyon Katsayısından yararlanılmış bu bağlamda; akıllı telefonları şarj ve kontrol etme aralığıyla öğretmenlerin nomofobi düzeylerinde anlamlı ve pozitif bir ilişki olduğu tespit edilirken; akıllı telefonlarını evde veya işyerlerinde unutunca panik olma durumları arasında ise yüksek düzeyde, pozitif anlamlı bir ilişki olduğu ortaya konulmuştur. Alan yazın incelendiğinde Sırakaya (2018), araştırmasında akıllı telefonları kontrol etme aralığıyla nomofobi arasında anlamlı bir fark olduğunu, kontrol etme sıklığı arttıkça nomofobinin de arttığını ortaya koymuştur. Panik olma durumu bağlamında ise, Sharma vd. (2015) tıp fakültesi öğrencilerinin çoğunluğunun (\%83) mobil cihazlarına erişememe durumunda panik atak geçirdiklerini saptamışlardır. 


\title{
EXTENDED ABSTRACT
}

\section{Investigation Of Teachers 'Nomophobia Levels According To Demographic Characteristics And Smartphone Use}

\author{
Ezgi Pelin Yıldız - Metin Çengel - Ayşe Alkan \\ Kafkas University, University of Applied Sciences, Ministry of National Education
}

Nomophobia, which is accepted as the disease of today, is defined as the fear of being deprived of mobile phone. The aim of this study is to reveal the changes in the nomophobia levels of teachers according to their demographic characteristics and smartphone usage habits.

When the related literature is examined, it is observed that nomophobia has different behaviors and symptoms. Individuals who exhibit nomophobic behavior and symptoms suddenly start to worry when they are not with their smartphones, when they are discharged and / or when they are out of range, and even need to control the devices obsessively even if they are with them (Adnan and Gezgin, 2016; Algül, 2014; Dixit). et al., 2010; Gezgin and Çakır, 2016; Pavithra and Madhukumar, 2015; Sharma, Sharma, Sharma and Wavare, 2015; Yildirim, Sumuer, Adnan, and Yildirim, 2015). In addition to such behaviors, the presence of symptoms such as dizziness, shortness of breath, stomach cramps, and anxiety in the health dimension is also noteworthy in the name of nomophobia (Thomee, Harenstam and Hagberg, 2011).

The study group of the research conducted in the relational screening model consists of 290 teachers working in public and private educational institutions and organizations in Sakarya province.

In the study, measuring problematic mobile phone use: Development and Preliminary Psychometric Properties of the PUMP Scale adapted by Merlo, Stone and Bibbey (2013) were used as data collection tools. The scale consists of 20 items.

Percentage $(\%)$, mean $(\mathrm{x})$, frequency $(\mathrm{f})$ and standard deviation (SD) were used in the analysis of the data collected to respond to sub-objectives. Kolmogorov-Smirnov test $\mathrm{p}>0.05$ value was obtained in the normal distribution of the data has been accepted. In this context, parametric tests; One Way Anova 
test was used. The general average was taken into account in explaining the differences of the data. In all statistical analyzes, 0.05 was accepted as the level of significance. The mean and standard deviation values of the items for the related survey are presented with the help of tables.

In this study, it has been tried to determine the changes in the nomophobia levels of the teachers according to their demographic characteristics and smartphone usage habits. According to this:

According to this, it was revealed that the most commonly used social media tool was "YouTube".

In the research, it was found that the majority of teachers kept the internet on their smart phones open during the day. This result is thought to be very important for nomophobicity.

Another result; the daily time spent by teachers on their smart phones was determined as " 6 hours and over". The control range of the smart phones was determined to be every 30 minutes.

Another finding is that most teachers experience a "panic state" when they forget their smartphones at home or at work.

In the research, it was observed that the majority of "teachers use smart phones in their cars"; however, "they did not send text-message-email in their cars". Another result is that teachers use their smart phones mostly for" social media".

In this study, the problematic smartphone usage and pre-psychometric properties scale developed by Merlo, Stone and Bibbey (2013) was used as a data collection tool in order to determine the nomophobic level of teachers. The scale consists of 2 dimensions and has a total of 20 items.

As a result, the highest average scale item is: "I realize that ignore the people (family, friends) who are with me while using my smartphone. The lowest average scale item is: "I am pessimistic and restless when I stop using my smartphone".

In the study, it was revealed that there was no significant difference between the teachers' gender, educational background, branch, institution and professional seniority and nomophobia levels.

In this study, it was revealed that the nomophobia levels of the teachers between 21-25 years of age were significantly higher than the nomophobia levels of the teachers aged 40 and over. 
In the research, it was found that there was a significant relationship between the levels of nomophobia and the levels that teachers worked; in this context, the nomophobia levels of pre-school teachers were found to be significantly higher than the nomophobia levels of primary, secondary and high school teachers.

There was no significant difference in nomophobia levels according to smartphone usage year; it was found that there was a significant difference between the range of charging and controlling smartphones and panic situations when they forgot their smartphones.

\section{Kaynakça / References}

Adnan, M., ve Gezgin, D. M. (2016). Modern yüzyılın yeni olgusu nomofobi ve üniversite öğrencileri arasında yaygınlı düzeyi. Ankara Üniversitesi Eğitim Bilimleri Fakültesi Dergisi, 49(1), 141-158.

Birbiri, D. (2013). Sosyal Medyanın Öğretim Amaçlı Kullanımına İlişkin Öğretmen Görüşleri. Yayınlanmış Yüksek Lisans Tezi, Kocaeli Üniversitesi, Eğitim Bilimleri Anabilim Dalı Eğitim Programları ve Öğretim Bilim Dalı.

Bragazzi, N. L. ve Del Puente, G. (2014). A proposal for including nomophobia in the new DSM-V. Psychology Research and Behavior Management, 7, 155.

Büyüköztürk, Ş. (2013). Sosyal bilimler için veri analizi el kitabı. Ankara: Pegem Akademi Yayıncilık.

Cresswell, J., W. (2017). Research Design: Qualitative, quantitative, and mixed methods approaches Fifth Edition. SAGE Publications.

Dixit, S., Shukla, H., Bhagwat, A. K., Bindal, A., Goyal, A., Zaidi, A. K. ve Shrivastava, A. (2010). A study to evaluate mobile phone dependence among students of a medical college and associated hospital of central India. Indian Journal of Community Medicine: Official Publication of Indian Association of Preventive \& Social Medicine, 35(2), 339.

Gezgin, D. M. ve Çakır, Ö. (2016). Analysis of nomofobic behaviors of adolescents regarding various factors. Journal of Human Sciences, 13(2), 2504-2519.

Gezgin D.M., Hamutoğlu N.B., Sezen-Gültekin G, Yıldırım S. (2019). Preservice Teachers' Metaphorical Perceptions on Smartphone, No Mobile Phone Phobia (Nomophobia) and Fear of Missing Out (FoMO) https://www.researchgate.net/publication/333893690 Preservice Teach ers' Metaphorical Perceptions on Smartphone No Mobile Phone Ph obia Nomophobia and Fear of Missing Out FoMO adresinden 27.12.2019 tarihinde erişilmiştir. 
Hoşgör, T. ve Hoşgör (2017). Nomofobinin günlük akıllı telefon kullanım süresi ve okul başarısı üzerindeki etkisi: Sağlık personeli adayları örneği. Akademik Sosyal Araştırmalar Dergisi 46 (5), 573-595.

Kaur, A., Sharma, P. ve Manu. (2015). A descriptive study to assess the risk of developing nomophobia among students of selected nursing colleges Ludhiana, punjab. International Journal of Psychiatric Nursing, 1(2), 1-6.

King, A. L. S., Valença, A. M., Silva, A. C. O., Baczynski, T., Carvalho, M. R. ve Nardi, A. E. (2013). Nomophobia: Dependency on virtual environments or social phobia? Computers in Human Behavior, 29(1), 140-144.

Kwon, M. vd. (2013). Development and validation of a smartphone addiction scale (SAS). PLoS One, 8(2), 1-7.

Lee, Y. K. vd. (2014). The dark side of smartphone usage: psychological traits, compulsive behavior and technostress. Computers in Human Behavior, 31, 373-383.

Merlo, L. J., Stone, A. ve Bibbey, A. (2013). Measuring Problematic Mobile Phone Use: Development and Preliminary Psychometric Properties of the PUMP Scale. Journal of Addiction, 2013, 1-7.

Monette, D.R., Sullivan, T.J. ve De Jong, C.R. (2005) Applied social research A tool for the human services. Thomson Brooks/Cole, London.

Pavithra, M. B., Madhukumar, S. ve Mahadeva, M. (2015). A study on nomophobia-mobile phone dependence, among students of a medical college in Bangalore. National Journal of Community Medicine, 6(3), 340344.

Schifferstein, H.N.J. (2006). The perceived importance of sensory modalities in product usage: a study of self-reports. Acta Psychologica, 121, 41-64.

Sharma, N., Sharma, P., Sharma, N., ve Wavare, R. R. (2015). Rising concern of nomophobia amongst Indian medical students. International Journal of Research in Medical Sciences, 3(3), 705-707. doi:10.5455/23206012.ijrms20150333.

Uysal, Ş., Özen, H. ve Madenoğlu, C. (2016). Social phobia in higher education: the influence of nomophobia on social phobia. The Global Elearning Journal, 5(2), 1-8.

Takao, M., Takahashi, S. ve Kitamura, M. (2009). Addictive personality and problematic mobile phone use. Cyber Psychology \& Behavior, 12(5), 501507. 
Yildirim, C. ve A.P. (2015), Correia Exploring the dimensions of nomophobia: Development and validation of a self-reported questionnaire Computers in Human Behavior, 49, 130-137.

\section{Kaynakça Bilgisi / Citation Information}

Yıldız, E. P., Çengel, M. ve Alkan, A. (2020). Öğretmenlerin nomofobi düzeylerinin demografik özelliklerine ve akıllı telefon kullanım alışkanlıklarina göre incelenmesi. OPUS-Uluslararası Toplum Araştırmaları Dergisi , 15(10. Yıl Özel Say1s1), 5096-5120. DOI: 10.26466/opus. 676329 